\title{
Prevalence and Correlation of Anxiety Disorders among Primary School Children in Nairobi, Kenya
}

\author{
Mathenge Justus*, Ayuya Caroline, Ongaro Kennedy, Khasakhala Lincolin \\ Daystar University, Kenya
}

*Corresponding Author: Mathenge Justus, Daystar University, Kenya

\begin{abstract}
The purpose of this study was establish the prevalence of anxiety disorders among primary school going children in Nairobi, Kenya. The study employed a descriptive study design utilizing purposeful sampling frame. The sample size of 224 was drawn from classes 3 to 7 at Our Lady Queen of Peace and Amani Primary Schools. Data was collected using a self-administered Socio-demographic and the Screen for Child Anxiety Related Disorders (SCARED) - Child Version. Findings showed the prevalence of anxiety disorders was extremely high (80.8\%) and were comorbid as is shown by positive correlation coefficient $(r)$ $p<0.001$ between the types of anxiety disorders. For specific anxiety disorders prevalence were: $66.5 \%$ had panic disorder, $56.3 \%$ generalized anxiety disorder, $81.7 \%$ separation anxiety disorder, $61.2 \%$ social anxiety disorder and 30.4\% significant school avoidance. This study therefore shows that children's mental health in an African cultural and environmental context wanting. These study findings can go a long way in helping the authorities concerned with health services to appreciate the need for a concerted effort in the formulation of policies and the need to provide resources to enhance mental health services in children attending primary school.
\end{abstract}

Keywords: Anxiety diorders, children, Correlation, Prevalence, Kenya

\section{INTRODUCTION}

Anxiety disorders are common in children (Wichstrom, Belsky, \& Berg-Nielsen, 2013).In a school setting they are characterized by excessive worry concerning the quality of their work, performance in examinations and how their future will be like (McLoone, Hudson, \& Rapee 2006). Children worry that they are not performing as well as they should and often seek reassurance from their teachers, parents and peers (Masi, Mucci, Favilla, Romano, \& Poli, 1999). According to the American Psychiatric Association (APA, 2013) anxiety disorders are characterized by excessive fear, anxiety and related behavioral disturbances.

The causes of anxiety in children are many. Rural/urban migration of parents looking for greener pastures results in many problems: socio-economic hardships of finding employment and adequate housing, negative influence on adherence to learned cultural practices and norms (The World Bank, 2008). Children between 8 and 13 years are in a stage in their development when they are supposed to be learning and internalizing the culture of the society (Papalia et al., 2004). Children in this study were exposed to this kind of environment where they continue to experience hard socioeconomic realities at their homes. This kind of situation and environment predisposes them to anxiety. King et al. (2005) estimated global prevalence of anxiety disorders among children to range between $5.7 \%$ and $17.7 \%$. Podell, Mychailyszyn, Edmunds, Puleo \& Kendall (2010) estimated the prevalence to be between 10 to $20 \%$. In a similar study, Tramonte and Willms (2010) estimated prevalence of anxiety among middle and secondary school students in Canada to range between $2 \%$ and $12 \%$.

"The global current prevalence for anxiety disorders is $7.3 \%$ (95\% CI 4.8-10.9\%), suggesting that one in 14 people around the world at any given time has an anxiety disorder and one in nine $(11.6 \%, 95 \%$ CI 7.6-17.7\%) will experience an anxiety disorder in a given year" (Baxter, Scott, Vos, \& Whiteford, 2012, p.5).

In Africa, model-based predictions show that prevalence of anxiety disorder is $5.3 \%$ with North Africa at $7.3 \%$ when adjusted for methodological factors. Compared with non-conflict populations Baxter et al. argued that conflict populations were $60 \%$ more likely to report anxiety. In Kenya, 
several different types of clinically significant anxiety syndromes were documented in a school survey among children and adolescent students utilizing different anxiety measuring instruments (Ndetei, Khasakhala, Mbwayo \& Mutiso, 2011). The Multidimensional Anxiety Scale for Children (MASC) instrument revealed that the prevalence was at $12.9 \%$ where most of the students $(>75 \%)$ had harm avoidance and social anxiety disorder. A questionnaire was utilized to screen a broad range of DSMIV defined anxiety disorder symptoms in children and adolescents in the same setting and almost all the students had separation anxiety, school phobia and obsessive or compulsive symptoms. The lowest anxiety symptoms (54.7\%) were in specific phobia for animals.

In their systematic review of risk factors, prevalence, and treatment of anxiety and depressive disorders in Pakistan, Mirza and Jenkins (2004) found that socioeconomic adversity and relationship problems were major risk factors for anxiety and depressive disorders. The mean overall prevalence of anxiety and depressive disorders in the community population was $34 \%$. This study therefore sought to establish the prevalence of anxiety disorders among primary school going children in Nairobi, Kenya

\section{Materials ANd Methods}

The study used a descriptive research design. The target population in this study comprised all students in classes 3 to 7 at Our Lady of Peace and Amani Primary schools in Nairobi County. These students were approximately 198 in number and they ranged from class 3 to 7 . This was the age group that Kendall, experimented with. Both schools are day schools for boys and girls.

The calculation of the sample size of 92 respondents was based on anxiety disorders prevalence rate given by Ndetei et al. (2011) who asserted that a large number of the Kenyan population has anxiety disorders and that anxiety disorders prevalence rate among children was at $12.9 \%$. The size of the sample was calculated using the method adopted from Chow, Shao \& Wang (2003).

\section{INCLUSION AN EXCLUSION CRITERIA}

All the children in the schools selected were those between 8 and 13 years of age. Children outside this age bracket were be allowed to participate. Also, children whopresented with psychosocial disabilities challenged were not included in this study. Children who did not assent to be included in the study or whose parents who did not consent to have them participate in the study were also excluded.

\subsection{Data Collection Instruments}

The following data collection instruments were found appropriate for the target population: the SocioDemographic Questionnaire. This questionnaire was developed and administered by the researcher. The purpose of this questionnaire was to collect details regarding the participants' age, gender, class, ethnicity, residence and type of accommodation, religious affiliation, parent(s) marital status, parent(s) employment and income and number of siblings. It also obtained data regarding any mediating and/or confounding variables that would have to be controlled for. For example family functioning, domestic violence, illness in the family and refusal to go to school were considered. The questionnaire was completed at the beginning of the intervention. The Screen for Child Anxiety Related Disorders (SCARED) - Child Version developed in 1995 by Birmaher was also used. It is rated on a Likert Scale from 0 to 2. Zero (0) indicates a not true or hardly ever true response. 1 indicates "somewhat true" or "sometimes true" response. 2 indicates "very true" or "often true" response.

\section{RESUlTS}

Table 1 tabulates prevalence of anxiety disorders. Using a cut-off point of 25 on the SCARED questionnaire, majority of the respondents were found to be anxious $80.8 \%$ (181). For specific anxiety disorders: $66.5 \%$ (149) had panic disorder, 56.3\% (126) generalized anxiety disorder, $81.7 \%$ (183) separation anxiety disorder, 61.2\% (137) social anxiety disorder and 30.4\% (68) significant school avoidance. This finding indicate that most of the respondents live with more than one type of anxiety disorder. 
Prevalence and Correlation of Anxiety Disorders among Primary School Children in Nairobi, Kenya

Table1: Prevalence Anxiety Disorder and Specific Anxiety Disorders

\begin{tabular}{|l|l|l|l|}
\hline \multicolumn{2}{|c|}{ Disorder } & \multicolumn{1}{c|}{ Frequency } & Percent \\
\hline \multirow{2}{*}{ Anxiety disorder } & No & 43 & 19.2 \\
\cline { 2 - 4 } & Yes & 181 & 80.8 \\
\hline \multirow{2}{*}{ Panic Disorder } & No & 75 & 33.5 \\
\cline { 2 - 4 } & Yes & 149 & 66.5 \\
\hline \multirow{2}{*}{ Generalized anxiety disorder } & No & 126 & 56.3 \\
\cline { 2 - 4 } & Yes & 98 & 43.8 \\
\hline \multirow{2}{*}{ Separation anxiety disorder } & No & 41 & 18.3 \\
\cline { 2 - 4 } & Yes & 183 & 81.7 \\
\hline \multirow{2}{*}{ Social anxiety disorder } & No & 87 & 38.8 \\
\cline { 2 - 4 } & Yes & 137 & 61.2 \\
\hline \multirow{2}{*}{ Significant school avoidance } & No & 155 & 69.2 \\
\cline { 2 - 4 } & Yes & 68 & 30.4 \\
\hline
\end{tabular}

Table 2 presents coexistence among the anxiety disorders. Using correlation coefficient (r), the finding indicate that the disorders were comorbid; positively correlated, almost all at $\mathrm{p}<0.001$. This finding indicate that the respondents lived with more than one anxiety disorder.

Table2: Correlation between Anxiety Disorders

\begin{tabular}{|c|c|c|c|c|c|c|}
\hline \multicolumn{2}{|c|}{ Disorder } & \multirow{2}{*}{$\begin{array}{l}\begin{array}{c}\text { Anxiety } \\
\text { disorder }\end{array} \\
.520^{* * *}\end{array}$} & \multirow{2}{*}{$\begin{array}{c}\text { Panic } \\
\text { Disorder }\end{array}$} & \multirow{2}{*}{$\begin{array}{c}\text { Generalized } \\
\text { anxiety disorder }\end{array}$} & \multirow{2}{*}{$\begin{array}{c}\text { Separation } \\
\text { anxiety } \\
\text { disorder }\end{array}$} & \multirow{2}{*}{$\begin{array}{c}\text { Social } \\
\text { anxiety } \\
\text { disorder }\end{array}$} \\
\hline \multirow[t]{2}{*}{$\begin{array}{l}\text { Panic } \\
\text { Disorder }\end{array}$} & $\begin{array}{l}\text { Pearson Correlation } \\
\text { (r) }\end{array}$ & & & & & \\
\hline & Sig. (2-tailed) & $<0.001$ & & & & \\
\hline \multirow[t]{2}{*}{ GAD } & $\begin{array}{l}\text { Pearson Correlation } \\
\text { (r) }\end{array}$ & $.486^{* *}$ & $.225^{* *}$ & & & \\
\hline & Sig. (2-tailed) & $<0.001$ & 0.001 & & & \\
\hline \multirow{2}{*}{$\begin{array}{l}\text { Separation } \\
\text { anxiety } \\
\text { disorder }\end{array}$} & $\begin{array}{l}\text { Pearson } \\
\text { Correlation(r) }\end{array}$ & $.450^{* *}$ & $.325^{* *}$ & $.278^{* * *}$ & & \\
\hline & Sig. (2-tailed) & $<0.001$ & $<0.001$ & $<0.001$ & & \\
\hline \multirow{2}{*}{$\begin{array}{l}\text { Social } \\
\text { anxiety } \\
\text { disorder }\end{array}$} & $\begin{array}{l}\text { Pearson Correlation } \\
(\mathrm{r})\end{array}$ & $.540^{* *}$ & $.269^{* *}$ & $.278^{* * *}$ & $.381^{* *}$ & \\
\hline & Sig. (2-tailed) & $<0.001$ & $<0.001$ & $<0.001$ & $<0.001$ & \\
\hline \multirow{2}{*}{$\begin{array}{l}\text { Significant } \\
\text { school } \\
\text { avoidance }\end{array}$} & $\begin{array}{l}\text { Pearson } \\
\text { Correlation(r) }\end{array}$ & $.315^{* *}$ & $.301^{* *}$ & $.277^{* *}$ & $.164^{*}$ & .090 \\
\hline & Sig. (2-tailed) & $<0.001$ & $<0.001$ & $<0.001$ & .015 & .178 \\
\hline
\end{tabular}

*Significant at $\mathrm{p}<0.05$ bolded

\section{DISCUSSION}

The study sought to establish the prevalence of common anxiety disorders among children. Table 1 tabulated prevalence of anxiety disorders. Using a cut-off point of 25 on the SCARED questionnaire, majority of the respondents were found to be anxious $80.8 \%$ (181). For specific anxiety disorders: $66.5 \%$ (149) had panic disorder, $56.3 \%$ (126) generalized anxiety disorder, 81.7\% (183) separation anxiety disorder, $61.2 \%$ (137) social anxiety disorder and 30.4\% (68) significant school avoidance. This finding indicate that most of the respondents live with more than one type of anxiety disorder. These findings can be compared to various studies that sought to establish the prevalence of anxiety disorders among children.

According to Barret, Fisak, and Cooper (2015) anxiety is one of the most prevalent mental illnesses in child populations, as young as preschool age. This is also supported by Edwards, Rapee, Kennedy, \& Spence (2010) who reported that in terms of childhood psychopathology, anxiety disorders are the most prevalent category of disorders. In a review to investigate prevalence of anxiety disorders among Iranian children Zarafshan et al. (2015) asserted that anxiety disorders were the most prevalent mental disorders involving 20-60\% of the group. In a review of depressed mood and anxiety by socioeconomic status in youth aged 10-15 years Lemstra, Neudorf, Kunst, Warren, \& Bennett (2008) concluded that prevalence of anxiety disorders in children is as high as $20 \%$ and above. 
In Africa Zarafshan et al. (2015) rated prevalence of anxiety disorders in Nigeria at $15 \%$. A study of selective Egyptian sample of out-patient at a clinic indicated a prevalence rate of $22.6 \%$. In Egypt a national survey of children aged between 10 and 18 years was carried out in 1999 reported $59 \%$ of 14,271 children as having experienced an anxiety disoder (Okasha, 2004). In Southern Ethiopia a study to determine the magnitude of specific mental and behavioral disorders in children indicated a rate of $24 \%$ for anxiety disorders. In Kenya, Ndetei et al. (2011) asserted that a large number of the Kenyan children population had anxiety disorder. On prevalence of anxiety disorder among children they put the prevalence rate at $12.9 \%$. All the studies discussed here strongly indicate how common and prevalent anxiety disorders are among the children and the need to provide treatment early to enable these primary going children develop well.

In regards to correlation of anxiety disorders, the study sought to determine common coexisting anxiety disorders presenting concurrent with anxiety disorder among children enrolled at Our Lady Queen Primary and Amani Primary Schools in Nairobi, County as presented in Table. Using correlation coefficient (r), the finding indicated that the disorders were comorbid; positively correlated, almost all at $\mathrm{p}<0.001$. In the current clinical sample, children had zero to six comorbid diagnoses, and $75 \%$ of children with a primary anxiety disorder met criteria for another disorder. The secondary diagnoses were most often other anxiety disorders, namely specific phobia $(n=)$, GAD ( $n=$ 98), Social anxiety $(n=137)$, Separation anxiety disorder $(n=41)$, Panic $(n=149)$ and significant school avoidance $(n=155)$. These findings are in line with several other authors, who also report high levels of comorbidity in samples of anxiety-disordered children.

Kendall and collaegues (2008), for example, also reported that $79 \%$ of children had at least one comorbid disorder. This large proportion of comorbidity may simply reflect the amount of overlapping features and symptoms. Comorbidity may also reflect the severity of the complaints or a general anxiety syndrome (e.g. Kendall et al., 2008), and may suggest that it is useful to emphasis on a general anxiety syndrome rather than on separate classifications. This study has provided evidence that the DSM-V clusters of anxiety are meaningful, but has also indicated some possible weaknesses of the dichotomous nature of DSM for childhood anxiety disorders. This study therefore concludes that most anxiety disorders coexist.

\section{CONCLuSion}

As research in anxiety disorders keep gaining momentum because of the impact these disorders have on children, this study has contributed to this development in terms of knowledge on assessment, considerations in treatment in clinical practice, and predictors of treatment outcome. This study showed significant amount of anxiety disorders among school going children in Nairobi, Kenya. Knowing that anxiety disorders negatively impact the functioning of children well being, academic performance, social relationships amongst other impacts, it is necessary for all Kenyan schools to consider mental health programs in school settings that are geared towards addressing and treating anxiety disorders. Intervention options such as Cognitive behavioral therapy that have been shown to be effective among children with anxiety disorders in Kenya, (Mathenge, 2019) may be utilized to reduce anxiety disorders among school going children.

\section{REFERENCES}

[1] American Psychiatric Association (2013). The Diagnostic and Statistical Manual of Mental Disorders fifth Edition. Washington, DC, American Psychiatric Association

[2] Baxter, A.J., Scott, K.M., Vos, T., \& Whiteford, H.A. (2013). Global prevalence of anxiety disorders: A systematic review and meta-regression. Psychol Med43: 2012 July 10: 897-910.

[3] Bowlby, J. (1969). Attachment and loss, Vol.1, New York, Basic Books. Cortina, M.A., Sodha, A., Fazel, M., \& Ramchandani, P.G. (2012). Prevalence of child mental

[4] Jenkins, R., Njenga, F., Okonji, M., Kigamwa, P., Baraza, M., Ayuyo, J., Singleton, N., McMannus, S., \& Kiima, D. (2012). Prevalence of common mental disorders in a rural district of Kenya and sociodemographic risk factors. International journal of environmental research and public health 2012, 9, 1810-1819.

[5] Kendall, P.C., Hudson, J.L., Gosch, E., Flannery-Schroeder, E., \& Suveg, C. (2008). Cognitive-behavioral therapy for anxiety-disordered youth: A randomized clinical trial evaluating child and family modalities. Journal of Consulting and Clinical Psychology, 76(2), 282-297 
[6] Masi, G., Mucci, M., Favilla, L., Romano, R., \& Poli, P. (1999). Symptomatology and Comorbidity of generalized anxiety disorder in children. Comprehensive Psychiatry, 40, 210-215

[7] Mathenge, J. (2019). Effectiveness of cognitive behavioral therapy (coping Cat program) on Anxiety Disorders among children in Our lady of Peace and Amani primary schools in Nairobi, Kenya. Unpblished thesis.

[8] McLoone J., Hudson J.L., \& Rapee R.M. (2006). Treating anxiety disorders in a school setting. Education and treatment of children Vol.29, 2, 219-242. West Virginia University Press, NSW 2109 Australia.

[9] Ndetei, D.M., Khasakhala, L., Nyambola, L., Ongecha-Owuor, F., Seedat, S., Mutiso, V., Kokonya, D., \& Odhiambo, G. (2008). The prevalence of anxiety and depression symptoms and syndromes in Kenyan children. Journal of child and adolescent health, Vol. 20, 1, 33-51, Nairobi, Kenya.

[10] Ndetei, D.M., Khasakhala, L.I., Mbwayo, A.W., Mutiso, V., (2011). Epidemiological patterns of anxiety disorders in Kenya, Africa medical health foundation (AMHF) Kenya. www.intechopen.com Retrieved on 8.7.2016

[11] Okasha, A., (2004). Focus on psychiatry in Egypt, The British Journal of psychiatry, 266-272

[12] Papalia, D. E., Olds, S. W., \& Feldman, R. D. (2004). Human development, ninth edition, New Delhi, Tata McGraw-Hill

[13] Papalia, D. E., Olds, S. W., \& Feldman, R. D. (2004). Human development, ninth edition, New Delhi, Tata McGraw-Hill

[14] Podell, J.L., Kendall, P.C., Gosch, E.A., Compton, S.N., March, J.S., Albano, A.M., Rynn, M.A., Walkup, J.T., Sherrill, J.T., Ginsburg, G.S., Keeton, C.P., Birmaher, B., \& Piacentini, J.C. (2013). Therapist factors and outcomes in CBT for anxiety in youth. Professional Psychology: Research and Practice, 44(2), 89-98.

[15] Podell, J.L., Mychailyszyn, M., Edmunds, J., Puleo, C.M., \& Kendall, P.C, (2010). A Coping (2010). The Coping Cat program for anxious youth: The FEAR plan comes to life. Cognitive and Behavioral Practice, 17(2), 132-141.

[16] Podell, J.L., Mychailyszyn, M., Edmunds, J., Puleo, C.M., \& Kendall, P.C. Cat program for anxious youth: the FEAR Plan comes to life, Association for behavioral and cognitive therapies. Elsevier Ltd.

[17] Tramonte L. \& Willms D. (2010). The prevalence of anxiety among middle and secondary school students in Canada. Canadian Journal of Public health/Revue Canadienne de Sante'e Publique, Vol. 101, 19-22. Canadian Public Health Association.

[18] UNICEF (2013). Children in the urban World. The state of the World's children (2012): New York (1):1-7 www.ncbi.nlm.nil.gov Retrieved on 8.7.2016

[19] Vine, M., Stoep, A.V., Bell, J., Rhew, I.C., Gudmundsen, G., \& McCauley, E. (2012). Associations between household and neighborhood income and anxiety symptoms in young children. Depression and Anxiety 29:824-832. Wiley Periodicals, Inc

[20] Wichstrom, L., Belsky, J., Berg-Nielsen, T. S. (2013). Preschool predictors of childhood anxiety disorders: a prospective community study. Journal of child psychology and psychiatry 54, 12, 1327-1336

[21] Zarafshan, H., Mohammadi, M., Salmanian, M. (2015). Prevalence of anxiety disorders among children and adolescents in Iran: A systematic review. Iranian Journal of Psychiatry 10

Citation: Mathenge Justus, et.al. "Prevalence and Correlation of Anxiety Disorders among Primary School Children in Nairobi, Kenya". International Journal of Humanities Social Sciences and Education (IJHSSE), vol. 6, no.12, 2019, pp. 134-138. doi: http://dx. doi.org/10.20431/2349-0381.0612011.

Copyright: (C) 2019 Authors. This is an open-access article distributed under the terms of the Creative Commons Attribution License, which permits unrestricted use, distribution, and reproduction in any medium, provided the original author and source are credited. 